\title{
SiAIS (Simple Alarm System) Based Light Dependent Resistor (LDR) and Basic Logic Gate as an Attempt to Preventing on Helmet Theft
}

\author{
Aji Rahmadi", Adi Ahmad Dimisa**, Asep Kurniawan ${ }^{* * *}$, Frida Agung Rakhmadi ${ }^{* * * *}$ \\ Physics Department, Faculty of Science and Technology, UIN Sunan Kalijaga \\ Jl. Marsda Adisucipto No. 155281 Yogyakarta, Indonesia. Tel. + 62-274-540971, Fax. + 62-274-519739 \\ Email: ajirahmadi64@gmail.com*, adi.ahmad.dimisa@gmail.com ${ }^{* *}$, asep.guncil@gmail.com ${ }^{* * *}$, frida.rakhmadi@uin-suka.ac.id ${ }^{* * * *}$
}

\begin{abstract}
Research on the Light Dependent Resistor (LDR) and the basic logic gates in the designing and manufacturing SiAlS (Simple Alarm System) as an attempt to Prevent theft helmet on had been done. This research was conducted aiming to create and Characterize alarm system. This study was intended to Prevent theft of the helmet. The method used in this research is divided into three stages, designing, manufacturing and testing. The working principle of this alarm system is when the helmet is mounted in the rearview mirror, the LDR will be closed so that the resistance increases the which causes the alarm to Become inactive. However, if the helmet is taken, the alarm will activate because The resistance decreases. However, the alarm will not work if the sensor cable is cut by the thief. To Overcome this problem, additional circuits are made using a NOT logic gates. The results of this research are prototypes in testing alarm systems and alarm systems get a 100\% success rate. The advantage of this alarm systems are cheap and simple, Because it does not use a microcontroller and can be made individually.
\end{abstract}

Keywords: Alarm, Helmet, Light sensors, Theft

\section{INTRODUCTION}

Concern about the theft of the helmet making related parties tightened security in the parking area of the motor. This can be seen in the campus parking areas or public places every day guarded by officers. Therefore, a large area and the attendant limitations in some places, it is considered less effective care. Despite breakthroughs have been done, but still a lot going on theft helmet.

To minimize this problem, the use of technology is the right step. Basically, the first human auditory rather than visual stimulated. Therefore, the technology can be used is a technology based on sound. Bikers can install a simple alarm in the place where the rearview motorcycle helmet. In a nutshell the alarm will sound when the helmet is taken if the alarm is not deactivated first. This of course can assist officers in overseeing the parking area.

Expectations of simple LDR-based alarm system is to reduce the theft of a helmet as well as creating rapid response officers when guard in case of theft so that the realization back a sense of security as well as eliminating concerns when the driver had to leave the helmet on a motorcycle.

\section{MATERIAL AND METHODS}

\section{Tools and Materials}

The tools used in this study is attached in Table 1.
Table 1. List of instrument used in the research.

\begin{tabular}{lll}
\hline No. & Type Tool & Total \\
\hline 1 & Solder & 1 piece \\
2 & Saw & 1 piece \\
3 & Ruler & 1 piece \\
4 & Electric drill and drill bits & 1 piece \\
5 & Scissor & 1 piece \\
6 & Knife (cutter) & 1 piece \\
7 & Fine sandpaper & 1 piece \\
8 & Stationary & 1 piece \\
9 & ACER laptop brands & 3 pieces \\
10 & Multimeter & 1 piece \\
11 & Camera & 1 Unit \\
\hline
\end{tabular}

Materials used in this study is attached in Table 2 .

Table 2. List of materials used in research.

\begin{tabular}{lll}
\hline No. & Type of Material & Total \\
\hline 1 & Sensor LDR & 1 piece \\
2 & Transistor BD 139 & 1 piece \\
3 & Led & 1 piece \\
4 & Timer IC 555 & 1 piece \\
5 & Capacitors 10mF & 1 piece \\
6 & Capacitors $1 \mathrm{mF}$ & 1 piece \\
7 & Resistor 10k & 1 piece \\
8 & Jumper & Sufficiently \\
9 & Buzzer & 1 Unit \\
\hline
\end{tabular}

\section{Manufacturing of Alarm System}

The block diagram of the steps for Alarm System is shown in Figure 1.

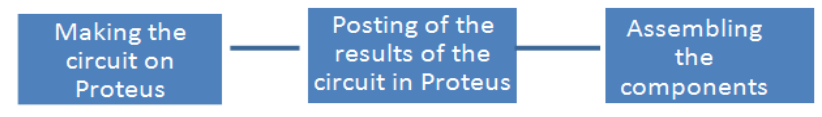

Figure 1. The procedures for alarm system. 


\section{Alarm System Testing}

Alarm System testing is aimed to determine the character of the sensor in the detector and determine whether the actual performance of the alarm system. Tests carried out on an alarm system that has been created with the aim to determine whether over time the system is working properly or not. Testing is done by giving each a 15-minute variation in 6 hours.

Precision alarm system can be obtained by using the equation

$$
\% \text { Presisi }=100 \%-\left[\frac{\Delta x}{F_{s}} \times 100 \%\right]
$$

Where $\Delta x$ is the greatest deviation and $F$ s is the maximum output.

\section{RESULTS AND DISCUSSION}

\section{Manufacturing of Alarm System}

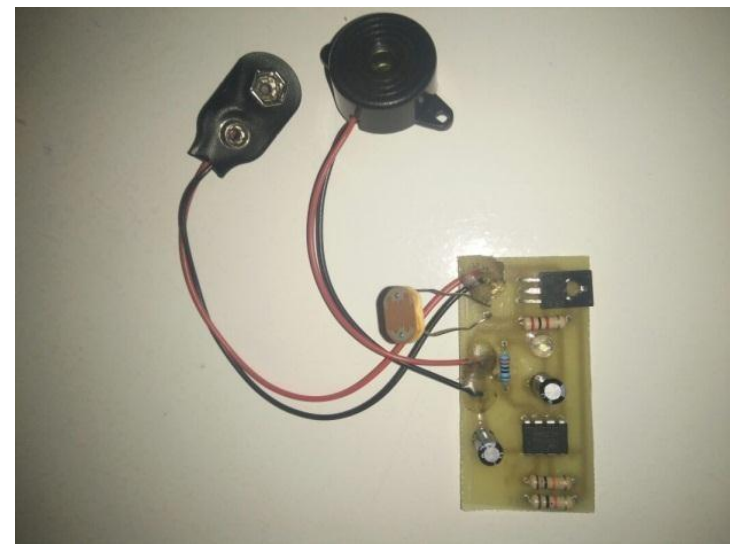

Figure 2. The result of manufacturing alarm systems.

This tool is applied to the motorcycle by using LDR mounted on Spion. Paired circuit system switch is placed hidden in a motorcycle. The most important thing that this tool works on motorcycles, needs to be connected to the ACCU motorcycle. However, ACCU has a voltage of 12 volts. Required additional voltage divider circuit so that the incoming voltage circuit is not too big. And also that the motorcycle horn can be connected to the tool, necessary Relay.

When the switch is turned on and a helmet placed on the rearview contained LDR, then the alarm will not sound. And when the helmet is taken, the alarm will sound. When we want to wear the helmet, the switch needs to be switched off first.

\section{Testing of Alarm System}

The alarm system testing process is done by closing the LDR sensor with a box that is considered a helmet. The test is carried out within 6 hours and the data is taken every 15 metrics. The output of this system is a sound that is flip-flop (high and low) where when high it will sound and when low it will die. From the data that can be obtained from the precision of this alarm system, where precision is the same as the repeatability obtained by repeating the data analysis process at different times. This tool has $100 \%$ precision in other words even though it is used repeatedly, the results will still be in accordance with the concept.

\section{CONCLUSIONS}

Base on research done, it can be conclude that the prototypes in testing alarm systems and alarm systems get a $100 \%$ success rate. The advantage of this alarm systems are cheap and simple, Because it does not use a microcontroller and can be made individually.

\section{REFERENCES}

Fraden, J. 2010. Handbook of Modern Sensors. New York: Springer Science and Business Media.

Gunarta, L. 2011. Transistor. 3.

Practicum, T.2017. Practical guide Basic Electronics. Yogyakarta: UIN Sunan Kalijaga. 